2020, Volume 10, International Conference Globalization, Innovation and Development. Trends and Prospects (G.I.D.T.P.), pages: 200-213 |

https://doi.org/10.18662/lumproc/gidtp2018/23

\section{Environmental Audit Contribution to the Evaluation and Control of Environmental Information}

\section{Sorina Geanina STĂNESCU ${ }^{1}$, Constantin Aurelian \\ IONESCU ${ }^{2}$, Mihaela Denisa COMAN $*^{3}$}

\section{${ }^{1}$ Valahia University of Targoviste, Institute of Multidisciplinary Research for Science and Technology, Targoviste, Romania, geaninastanescu@yahoo.com}

\section{${ }^{2}$ Faculty of Economics, Hyperion University of Bucharest, Bucharest, Romania, ionescuaurelian89@gmail.com}

${ }^{3}$ Valahia University of Targoviste, Institute of Multidisciplinary Research for Science and Technology,

Targoviste, Romania, cmndenisa@yahoo.com Corresponding author
Abstract: The importance of environmental information at international level has contributed to the evolution of environmental reporting of economic entities, both in the annual financial statements and in special reports dedicated exclusively to environment and sustainable development. Thus, a new concept - environmental audit - emerges as an instrument for the certification and control of environmental information in accordance with legal regulations. Environmental auditing has been developed to reduce the environmental costs and recognized sanctions for industrial accidents with environmental and human impacts. The main purpose of this research is to present how the environmental audit contributes to the evaluation and the control of the environmental information, which are published by the enterprise whose activity have an significant impact about the environment. Environmental auditing is a voluntary activity, standardized by independent, non-regulatory professional bodies. The research undertaken is part of constructive, positivist research, using descriptive analysis as the main method of research. The source of the information used in this article is the study of scientific papers in the field of environmental auditing, scientific papers in the field of environmental and accounting researches regarding the environment of the normative acts, as well as other reports and communications on environmental information and the international standards applicable on environment field.

Keywords: environmental auditing; environmental accounting; environmental remediation costs; environmental management system.

How to cite: Stănescu, S.G., Ionescu, C.A., \& Coman, M.D. (2020). Environmental Audit Contribution to the Evaluation and Control of Environmental Information. In I. Panagoreț \& G. Gorghiu (vol. ed.), Lumen Proceedings: Vol. 10. International Conference Globalization, Innovation and Development. Trends and Prospects (G.I.D.T.P.) (pp. 200-213). Iasi, Romania: LUMEN Publishing House.

https://doi.org/10.18662/lumproc/gidtp2018/23 


\section{Introduction}

The environmental audit concept first appeared in the United States for the purpose of assessing the environmental performance of the oil and chemical industries [1]. Environmental auditing has the role of reducing the costs of remedies and sanctions recognized in the case of industrial accidents with environmental and human impacts, as well as the desire to manage the environmental impact and performance [2]. To minimize environmental impact in developed countries introduced a specific regulation and standardized and well documented to monitor all relevant issues causing pollution [15]. With regard to the natural environment, environmental audit is developed as an instrument by which organizations respect the norms from the point of view of their own assessment and information, as well as the creation of competitive advantage in the context of the current global crisis environment. Changing the attitudes of entrepreneurs to the environment has recently been based on various factors such as $[9,15]$ : the development of international and national policies, the consolidation and development of the awareness environment, the introduction of eco-labels, the creation of the image of the environment, environmental costs, reducing resource consumption, increasing the level of education and training environmental specialists. In a study realised by KPMG regarding the publication of environmental information, it was demonstrated that most businesses audit their environmental reports independent of the financial reports and that their number is steadily rising, from 18\% in 1999 to 2005 when the study has been reached has reached 30\% enterprises that audit environmental reports [1].

The purpose of this research is to present how the environmental audit contributes to the assessment and control of environmental information published by the enterprise in relation to the environmental impact of economic activity. We will analyze the field of environmental auditing as a concept and typology, the involvement of financial auditing and the accounting profession in auditing environmental information as well as environmental management systems as possible variants to improve the environmental performance of enterprises [4]. 


\section{General considerations on environmental audit}

The environmental audit is a management tool that involves systemic, documentary, periodic and objective assessment of environmental performance designed to facilitate the control of environmental issues [17]. The Confederation of the British Industry defines environmental auditing as a systematic examination of the interactions between any economic and environmental operations. These include emissions to air, soil, water, and impacts on neighboring areas, public perception on enterprise activity by the local community [1]. The environmental audit does not analyze all legislative provisions, but does a strategic approach to the business [18]. In an expanded context, environmental audit is defined by Philippe Peuch-Lestrade as a management tool that allows comprehensive, documented, periodic and objective assessment of how an enterprise's management integrates the environment, facilitating the organization and control of environmental practices [1]. We consider the environmental audit as a managerial tool, which evaluates the environmental aspects in order to obtain certification of the information provided.

Over time, depending on the purpose and objective of the audit, several types of environmental auditing [14] have been developed that have been taken over by academia and recognized professional bodies. A classification of the environmental audit, which we consider relevant, is grouped into three main categories [16]: audits to obtain assurance that the company's activity is within the legal environmental regulations; audits that address the environmental management system [7]; pollution prevention audits.

The first large group includes the types of audit that are performed to ensure that the company's business is in line with current and future environmental regulations, thus avoiding possible liabilities, responsabilities, environmental debts [16]: Audit of compliance is the most usual form of audit that consists of a process of verifying compliance between the policies promoted by the company with environmental legislation (emission limits, operating permits, waste disposal, etc.); Audit for risk assessment is a specialized field for experts in the assurance, the audit objective focuses on the potential occurrence of events generating environmental damage and the assessment of their consequences; the risk assessment identifies the technological flow points in which environmental accidents can occur (starting with raw materials supply, productive processes, storage and distribution; Pre-acquisition audit is the environmental audit carried out prior to the purchase of land, building; may in some cases 
involve sampling and tests designed to quantify the size of possible previous environmental damage as well as future remediation costs; the results of this type of audit can alter the value of the investment and also help to clearly part responsibilities; Audit for labor protection and assurance.

The second audit group addresses the environmental management system. The audit of environmental management consists of analyzing the environmental performance of the enterprise, for checking the management of the external environment (ISO 14001 or EMAS) and internal (in the case of multinational groups): The enterprise audit (initiated by the company's managers in order to verify the organizational structure, the roles and responsibilities, how to enforce environmental policy, reports on communication of information within different subsidiaries); System audit (is specific to verifying an environmental management system in accordance with one of the ISO 14001 or EMAS standards); Audit of environmental policy (requires control of the existence of environmental policy, specific and comprehensive for all significant environmental aspects of the enterprise and the manner in which it is communicated to and appropriated by all employees).

From the third category, that of the pollution prevention audit, we mention: Site and activity audit (an exhaustive environmental audit but limited to a single activity or plant that combines many of the elements of the other types of audit); The waste audit (divided into two sides, the first identifies and quantifies the sources of waste generation and is the starting point for their minimization programs at source, the second part analyzes waste management (practices, procedures) incorporating issues related to contractual agreements with other companies, authorities, etc. for their collection and storage); Product auditing (takes into account the impact of environmental products across the different phases: design, manufacturing, use, storage, packaging, etc.). The full environmental impact assessment involves analyzing the product life cycle, the stage needed to achieve an eco-markings or "green" registration); Audit of cross - sectoral activities (It addresses those activities that cross several sectors of interest to the enterprise).

Another classification of the environmental audit is that based on the objective of the audit, as follows: external environmental audit (providing stakeholders with certainty as to the accuracy of the information contained in the environmental reports and having as objective the assessment of environmental conditions at the local or regional level), respectively the internal environmental audit (to inform the management on the compliance of the operations with the regulations and the environmental legislation). 
The internal environmental audit focuses mainly on two directions [2]: Assessing the impact of enterprise's led policy through a systematic study of environmental activities, objectives, services, practices; Audit of the management system through a review of the procedures and structures by which the environmental policy is conducted by the enterprise. These types of audit presented illustrate the wide variety of issues that come under the heading of environmental audits, also demonstrating that many elements can be communicated in different types of audit. It is essential, however, that both the audit objectives and the boundaries in which the audit is conducted should be established from the stage of the audit plan.

In the long run, the ultimate goal of environmental auditing is to enable the management system to be assessed and improved, and also to identify and address environmental issues, identify the risks or dangers that may arise. The way companies implement these alternatives to the organization of the environmental audit depends on each individual enterprise, so [11]:

- Undertakings whose economic activity has a low environmental impact or small businesses will monitor and control environmental information as part of the internal control system;

- Enterprises with high environmental risk can design and implement a separate internal control subsystem in accordance with ISO 14000, EMAS;

- Other businesses use all controls in an integrated system, including policies and procedures related to accounting, environmental, and other aspects such as health, quality and safety.

Performing the environmental audit presents the following a number of advantages, the most important ones that we consider are highlighted in Fig. 1. 


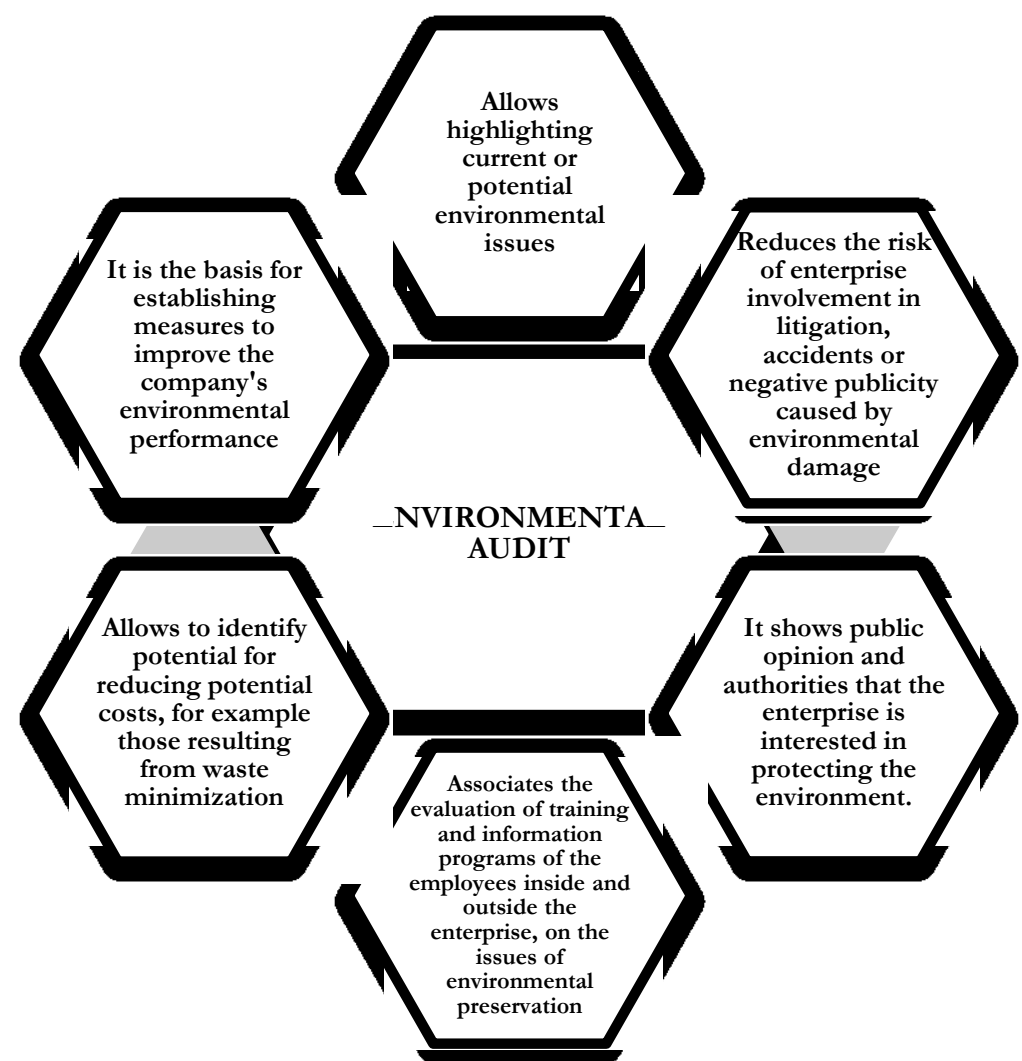

(Source: Betianu L, Georgescu I. Approaches of environmental information audit in annual reports. Annales Universitatis Apulensis Series Oeconomica. 2008;1(10):1-8.)

Figure. 1. Main advantages of environmental audit

Other benefits of using environmental auditing by businesses [16], including: replacing hazardous substances that affect the environment and, implicitly, our environment with environmentally friendly materials; the development [10] of new widely accepted products; enterprise training for investors or for association opportunities; identifying the training needs and staffing needs; protecting natural resources and ensuring a clean environment for future generations; increasing employees' competitiveness in relation to environmental issues; increases the credibility of the enterprise with regard to efforts to ensure the quality of the environment and improves the public image with advantages in terms of competitiveness; provides a database for decision-making and allows for better managerial practices.

Arguments against environmental auditing arise when noncompliances or even flagrant violations of environmental regulations are identified [5]. Implementing and conducting environmental audits requires 
relatively high costs related to the preparation of this process, which is one of the main drawbacks of environmental audit.

\section{Involvement of financial audit in the certification of environmental information}

As defined by the American Accounting Association, the environmental audit is a systematic process regarding the certification of economic actions, in order to evaluate the degree of compliance with these statements with predetermined criteria, as well as to communicate the results to interested parties [25]. Another definition that we consider to be representative of the financial audit is that "the financial audit consists of collecting audit evidence about an entity's financial statements and using these evidence to assess their compliance with pre-established criteria" [19]. Thus, we can observe that the audit is the activity specific to the assessment and compliance of the information contained in the financial statements against a set of criteria, and to issue an opinion according to the identified accounting referential (ISA 200).

The International Audit Practice Committee has defined the environmental information taken over by the financial audit as [12]: actions to prevent, reduce or remedy environmental damage or to conserve recyclable or non-recyclable resources; the consequences of noncompliance with legal regulations regarding the environment; the negative impact on natural resources; consequences of indirect obligations imposed by law.

Because the content of environmental reports is not regulated, the information published thereon is subject to certification, thus for auditing environmental information under IASP 1010 [11]: the valuation of fixed assets is analyzed, for example, in response to changes in environmental legislation or other business strategies, appreciating their influence on them. For this, asset valuation policies and procedures are dealt with in situations where their depreciation has occurred due to environmental factors; It compares estimates of site-bound obligations with estimates of liabilities for other sites with similar environmental issues; current costs incurred for other similar sites; estimate the environmental costs reflected in the sales prices; Checks and evaluates the documentation on the basis of which the amounts of the environmental obligations, any provisions or any debts have been settled and such documentation is discussed with those responsible; It analyzes the relevance of presenting the effects of environmental problems on the financial reports. 
Environmental information has a significant impact on the enterprise's financial statements, so they have become important to an increasing number of businesses, national and international organizations, governments and other users of financial statements. As we can see, environmental information can have implications for financial statements and can influence the views of financial auditors. Incomplete disclosure of environmental issues in the enterprise's financial statements may distort the continuity of economic activity, may lead to depreciation of assets and a reduction in their carrying amount, which leads to the presentation of a qualified opinion by financial auditors. [26] Also, an environmental audit requires skills in various fields, and a reasonable way to organize such an audit can be teamwork, involving auditors, accountants, engineers, or other environmental experts [13].

\section{Environmental management systems}

At a global and European level, more and more businesses are concerned about achieving environmental performance by controlling the environmental impact of their own activity and, at the same time, developing their ability to demonstrate to others that performance, it is not sufficient to carry out analyzes or to carry out the environmental audit in order to be sure that their performances satisfy and meet the legal requirements and their own environmental objectives, an integrated system in environmental management is required.

Environmental management system contributes to the proper allocation of environmental problems, ensures the adoption of specific practices and procedures designed to ensure the smooth functioning of the activities of these organizations [24]. The environmental management system is characterized by a series of phases including environmental auditing and international standards [2].

An environmental management system (EMS) is the component of the organization's overall management system, consisting of the organizational structure, planning, responsibilities, processes, practices, procedures and resources that help build, create, implement, review and maintain environmental policy of the organization. The implementation of an EMS allows the companies not only to meet its expectations regarding environmental performance but also to reduce its environmental costs and respect the environmental regulations. The environmental management system is thus an environmental impact management system that monitors the company's environmental performance [13]. 
Adopt environmental policy to continually improve environmental performance;

Performing an interim verification to identify potential environmental issues;

Elaboration of environmental programs with objectives, goals and concrete actions;

Adopt an EMS to carry out specific activities to achieve the objectives;

Regular organization of environmental audit to measure environmental performance and environmental impact;

Elaboration of a declaration on environmental performance;

Obtaining independent certification of the environmental report through external audit.

Source: adaptation after Caraiani C. (coord.) |"Green Accounting - Transdisciplinary

Strategies to Social and Environmental Accounting. Studies and research". Bucharest:, Ase Publishing, 2010

Figure. 2 The phases of development and implementation of environmental management

The key to the success of such a system is the assumption of responsibilities at all levels, especially at the top management level. The main purpose of an EMS is to ensure environmental protection, to reduce pollution and to ensure a balance between environmental, social and economic issues. The application of such a system allows the organization to establish and evaluate the effectiveness of environmental policies. Regarding the relationship between environmental accounting and the EMS, Fortes (2003) [8] pointed out that for a successful management 
system requires a method for managing environmental costs and integrating and using these costs in the business decisions of the system.

As a conclusion of the presented, we can say that environmental management is a component of the enterprise management system, necessary for the calculation of environmental performance, for the integration of environmental costs and for the efficient management of the environment.

An EMS is certified by International Organization for Standardization and by Environmental Management and Audit Scheme. The environmental management system is subject to ISO 14000 standards and can be applied to any enterprise of any size. Standards in the ISO 14000 family cover a five-tier action line: environmental management systems, environmental audit [28], assessment of the protection of human communities against adverse industrial activities, environmental classification, life cycle assessment of products and services. The user guide provided by ISO 14000 provides requirements for integrating environmental management into the overall management structure of the organization. In practice, this is based on the environmental policy adopted by the organization. ISO 14000 are general standards for EMS and control the environmental impact. These standards include the EMS models that can be implemented by an organization. These provide the tools needed to evaluate environmental performance, preliminary analysis and environmental assessment of the organization's sites.

ISO 14001 is the reference standard of the ISO 14000 series for EMS and describes the main information that an environmental management system must respect [3]. An environmental management system according to ISO 14001 offers a systematic and consistent framework for improving environmental performance, respecting environmental legislation and preventing non-compliance [6]. Although the main objective of implementing an EMS is to reduce the negative impact of the organization's activities, products and services on the environment [22]. Among the most important is the increase of profit by optimizing the use of resources (raw materials, energy), by improving the waste management and reducing the costs related to possible environmental incidents.

Such an EMS can be applied to those activities and "environmental issues" that the organization can control and influence. An EMS is applicable to any organization that wants to: a) Implement, maintain and improve an EMS; b) Respect the environmental policy; c) Demonstrate this to stakeholders; d) Certification / registration of the EMS by an 
external body; e) to carry out a self-assessment and a declaration of compliance with the International Standard ISO 14000.

The Ecological Management and Audit Scheme (EMAS) is one of the main tools of the European Union by which companies and other organizations evaluate report and improve the environmental impact of their work [20]. The EMAS program was regulated by the Council of Europe on 29 June 1993 (regulation 1836/1993) for industrial enterprises, and in 2001 it should be extended to all areas including public and private services (regulation 761/2001) [3] . EMAS is a European environmental management tool designed to support organizations in the continuous improvement of environmental performance by integrating the concept of sustainable development [21].

Employer registration and certification within the EMAS management scheme brings the following benefits [27]: provides a better image and and increases the credibility of customers, partners, investors and the local community; competitive advantage on the national and European markets by improving environmental performance; giving new business opportunities to markets where organic production processes are important; from an economic point of view, it means: saving resources and lower costs, thus reducing the financial burden caused by reactive management strategies, such as remediation, payment of penalties for violating legislation.

The difference of these two standards [23] is that EMAS applies only at European level, but the ISO standard applies internationally, no matter the continent. Initially, EMAS was used to certify the activities of industrial enterprises, but today it applies to any type of enterprise as in the case of ISO standards. Another difference [23] is that companies applying EMAS need to draw up an environmental statement after they have been audited by an accredited person, while ISO 14001 does not provide this obligation, so we can assume that the class of standards ISO is less restrictive than the EMAS scheme.

In Romania, the application of standards in order to achieve a high-performance environmental management is not an obligation, so companies can apply these standards according to the environmental problems they face. The Romanian Standardization Institute, made up of environmental specialists, was tasked with adopting the ISO 14000 series of international standards. In Romania, the EMAS scheme was regulated in 2004 when the Ministry of Agriculture, Forestry, Rivers and the Environment has established the organization and coordination procedure for the voluntary participation of organizations in these schemes. 


\section{Conclusion}

After the preparation of the environmental financial accounting or other report form, which has as main purpose the presentation and publication of the obtained environmental information, a final step could be the auditing of these reports either by using the audit of the financial statements or the audit external environment. We believe that environmental auditing is the key tool for assessing how the enterprise is managing environmental information in order to achieve a high level of environmental performance. Environmental audit is also a basic pillar in ensuring a true image of the impact of economic activity on the environment. As presented in this study, environmental auditing brings many benefits to economic entities, but it can also have disadvantages, most often related to the high cost of doing it.

Another tool necessary for a more efficient assessment and management of environmental information by the enterprise is the environmental management system, a component of the enterprise's overall management system. At national level, the most well-known environmental management system standards are the international standards ISO 14001 and EMAS (Environmental Management and Auditing Scheme), standards that help to improve the image of the enterprise, better credibility for investors and authorities.

As a final conclusion, the research undertaken in this study promotes the importance of environmental auditing, the integration of the accounting profession in its implementation, and the implementation of an environmental management system by national enterprises for sustainable management and accountability of economic activity.

\section{References}

[1]. Betianu L, Georgescu I. Approaches of environmental information audit in annual reports. Annales Universitatis Apulensis Series Oeconomica. 2008; 1(10): 1-8.

[2]. Caraiani C. (coord.) Green Accounting - Transdisciplinary Strategies to Social and Environmental Accounting. Studies and research. Bucharest: Ase Publishing; 2010.

[3]. Campos LM, de Melo Heizen DA, Verdinelli MA, Miguel PA. Environmental performance indicators: a study on ISO 14001 certified companies. Journal of Cleaner Production. 2015 Jul 15; 99: 286-296.

[4]. Cook W, Van Bommel S, Turnhout E. Inside environmental auditing: effectiveness, objectivity, and transparency. Current Opinion in Environmental Sustainability. 2016 Feb 1; 18: 33-39. 
[5]. De Moor P, Beelde ID. Environmental auditing and the role of the accountancy profession: a literature review. Environmental Management. 2005 Aug 1; 36(2): 205-19.

[6]. Dogui K, Boiral O. Permanence de l'auditeur et indépendance de l'audit ISO 14 001: une étude exploratoire. VertigO-la revue électronique en sciences de l'environnement. 2013 Oct 1; 13(2).

[7]. EMAS, Eco-Management and Audit Scheme. Available from: http://europa.eu.int/comm/environment/emas/index _en.html [Accessed 2nd February 2019].

[8]. Fortes H. The need for environmental reporting by companies: an examination of the use of environmental reports by Swedish public companies. Greener Management International. 2003; 40.

[9]. Gray R. Current developments and trends in social and environmental auditing, reporting and attestation: $\mathrm{A}$ review and comment. International journal of auditing. 2000 Nov 1; 4(3): 247-68.

[10]. Hammond A, World Resources Institute. Environmental indicators: a systematic approach to measuring and reporting on environmental policy performance in the context of sustainable development. Washington, DC: World Resources Institute; 1995 May.

[11]. IAPS - International Auditing Practice Statements. The consideration of environmental matters in the audit of financial statements, Annex no. 2. 1998.

[12]. IAPS. International Auditing Practice Statement (IAPS) 1010 - Consideration of Environmental Considerations in Financial Statements Audit; 2004.

[13]. Ienciu AI, Cioara MN. Instruments that are need to ensure the credibility of environmental information. Global Journal of Management And Business Research. 2010 Jun 20; 10(3).

[14]. Liu XF, Liu YY, Wu XL. Study on Corporate Environmental Auditing based on Environmental Management Systems. 2016 3rd International Conference on Social Science (ICSS 2016): 644-649. ISBN: 978-1-60595-410-3.

[15]. Ljubisavljević S, Ljubisavljević L, Jovanović D. Environmental Audit for Environmental Improvement and Protection. Economic Themes. 2017 Dec 1; 55(4): 521-38.

[16]. Macoveanu M, Ciubotă-Roşie C. Environmental audit. Ecozone; 2003.

[17]. Meyronneinc JP. Le management de l'environnement dans l'entreprise. Association française de normalisation. Ed. Afnor, Paris; 1994.

[18]. Negrei CC. Tools and Methods in Environmental Management. Bucharest: Economica Publishing; 1999.

[19]. Oprean I, Popa IE, Lenghel RD. Audit and financial control procedures. Risoprint; 2007.

[20]. Petrosillo I, De Marco A, Botta S, Comoglio C. EMAS in local authorities: Suitable indicators in adopting environmental management systems. Ecological indicators. 2012 Feb 1;13(1): 263-274. 
[21]. Radu M. Corporate governance, internal audit and environmental audit-the performance tools in Romanian companies. Accounting and Management Information Systems 11.1; (2012): 112.

[22]. Semal N. Intermédiaires et dynamique des réseaux fluides. $\mathrm{Du}$ mode d'existence de la norme ISO 14001 en Région wallonne. Diss. Arlon, Belgique: Université de Liège; 2011.

[23]. Testa F, Rizzi F, Daddi T, Gusmerotti NM, Frey M, Iraldo F. EMAS and ISO 14001: the differences in effectively improving environmental performance. Journal of Cleaner Production. 2014 Apr 1; 68: 165-73.

[24]. Thompson D, Wilson MJ. Environmental auditing: theory and applications. Environmental Management. 1994 Jul 1; 18(4): 605-15.

[25]. Tiron TA et al. Fundamentals of Financial Audit. Cluj Napoca: Accent Publishing; 2009.

[26]. Todea N, Stanciu IC, Joldos AM. Environmental audit, a possible source of information for financial auditors. Annales Universitatis Apulensis: Series Oeconomica. 2011 Jan 1; 13(1): 66.

[27]. http://www.mmediu.ro/ [Accessed 3rd February 2020].

[28]. Xiao-Feng LI, Yang-Yang LI, Xiao-Ling WU. Study on Corporate Environmental Auditing based on Environmental Management Systems. DEStech Transactions on Social Science, Education and Human Science; 2016. 